\title{
Ecological Feasibility of Applying Technology in Recycling Garment and Knitwear Production
}

\author{
Olga KADNIKOVA ${ }^{1 *}$, Gulnara ALTYNBAYEVA², Sergey KUZMIN ${ }^{3}$, \\ Arman AIDARKHANOV ${ }^{4}$, Medet TORETAYEV ${ }^{5}$, Zauresh KHABDULLINA ${ }^{6}$ \\ ${ }^{1-6}$ Rudny Industrial Institute, 50 let Oktyabryastreet 38, Rudny, 111500, Republic of Kazakhstan

\begin{abstract}
The paper deals with the problem of processing garment and knitwear production by recycling garment and knitwear. In this research was made a comparative assessment of the methods for producing knitted fabric from recycled yarn using various technological auxiliary equipment for recycling. The author gives a qualitative and environmental-economic assessment of the developed technology for obtaining a cloth of recycled yarn.
\end{abstract}

Keywords - Model of device for processing the yarn waste; physical-mechanical properties of the knitted fabric; production waste; zero waste technology

\section{INTRODUCTION}

Improvement of living standards of the Kazakhstan population is reached with the exponential growth of the gross domestic product by means of non-renewable natural resources. Out of them only $2 \%$ are used in the form of ready-to-use products, other $98 \%$ pollute the environment through waste emissions [1]-[3]. This requires urgent and drastic measures to be taken for reducing significantly the consumption of non-renewable resources, environment pollution and diseases. The priority in this direction is recycling of the production waste for obtaining of ready products, which allows reducing significantly the use of natural resources, cutting 2-3 times the volume of works and energy consumed for waste recycling compared to the primary production and, consequently, reducing the environment pollution.

Waste of the garment and knitwear industry are materials exposed to very complicated technological processing, having a definite chemical composition and properties, being in a definite state of matter. In the process of stable production, a sufficient amount of waste is formed on a regular basis.

Analysis of the ways of waste recycling of the garment and knitwear industry showed that in the national practice technological waste of light industry and secondary material resources comprise $25 \%$ of the entire recycled textile raw materials in Kazakhstan representing huge reserves for manufacturing of new articles [4], [5]. However, basically only $10 \%$ of this waste is recycled into nonwoven fabric of different purpose or into products having simpler manufacturing technology in the form of oakum, upholstery batting and technical cotton-wool, cleaning ends, etc. [3]. The rest of the waste is disposed of or thrown away.

\footnotetext{
* Corresponding author.

E-mail address: kadnikovaolga@mail.ru
}

(C)2019 Olga Kadnikova, Gulnara Altynbayeva, Sergey Kuzmin, Arman Aidarkhanov, Medet Toretayev, Zauresh Khabdullina. This is an open access article licensed under the Creative Commons Attribution License (http://creativecommons.org/ licenses/by/4.0), in the manner agreed with Sciendo. 
The existing technologies of waste recycling are accompanied by significant amount of organic and inorganic dust emission from equipment (manufacturing of nonwoven fabric, oakum, upholstery batting and technical cotton-wool). Frequently concentration of textile dust in the industrial premises exceeds the maximum permissible concentration. Textile dust, being highly hazardous, causes different diseases, at the same time it reduces the quality of products.

Provision of light industry enterprises with modern technological equipment allows minimizing the emissions of harmful substances into atmosphere or completely disposing of and regenerating the production waste [5], [6]. However, introduction of such environmentally "clean" technologies require big investment. Thus, only expenses on purifiers comprise around $25 \%$ of the article's prime cost. Such technologies and equipment are not affordable to small enterprises. Many other auxiliary devices also require significant investment and may not solve the environmental issues efficiently.

For this reason, development and improvement of methods and devices for recycling of waste of the garment and knitwear industry in Kazakhstan is of fundamental importance for maximum involvement of material and raw resources for manufacturing of products of mass consumption. It is particularly relevant now when large garment and knitwear industry enterprises are being replaced with basically medium and small private enterprises, which cannot afford new environmentally friendly equipment for recycling of the production waste. Developed methods and devices of waste recycling may be applied at any garment and knitwear enterprise and will allow solving not only the environmental problems, but also receiving additional profit from sale of valuable raw materials.

According to the analysis of scientific technical literature, at the current stage of development of the science the actual amount of research on waste recycling of the garment and knitwear industry on an industrial scale is insufficient. Successful work on obtaining high-quality materials from industrial waste is mainly the work of scientists related to the production of completely new products from potatoes [7] and fish production waste [8] associated with the processing of household garbage, reducing the use of equipment with high environmental costs [12], as well as reducing fuel and electricity, emit an increased amount of carbon dioxide into the atmosphere [13].

For example, the joint work of the authors of Riga Technical University and the Institute of Energy Systems and Environment. Scientists Vivita Priedniece, Kriss Spalvins, Kaspars Ivanovs, Jelena Pubule, Dagnija Blumberga in the work "Bioproducts from Potatoes. A Review" are considering the possibility of using potatoes for the production of new materials, such as bioplastic [7]. The authors Kriss Spalvins, Dagnija Blumberga in "Production of Fish Feed and Fish Oil from Waste Biomass Using Micro-organisms: Over view of Methods Analysing Resource Availability" are searching for new alternatives to traditional fish meal and fish oil [8].

Over the past 10 years a significant amount of work on recycling garment and knitwear production were published. Russian scientists Vatstl A. [9], Azimovoy Sh. G. [10] carried out a number of works in the field of obtaining high-quality materials from knitwear production waste. Many works of the authors from Kyrgiziya like Imankulova A. S., Moldokanova A. I. and others are devoted to research and analysis of textile and garbage wastes at Bishkek enterprises [11].

A necessity of fundamental research in this direction is related to a new step in the development of such sciences as material science of textile industry, technological equipment of the industry, resource-saving technologies, etc. The major direction in this relation is reuse of the production waste for obtaining of ready products, which would allow reducing the use 
of natural resources significantly, cutting 2-3 times the volume of works and energy consumed for waste recycling compared to the primary production and, consequently, improving the environmental situation.

In the process of knitting at garment and knitwear factories a low level of skills of personnel in maintenance of the equipment, insufficient attention to its technical condition in a work process may lead to defects in semi-finished products of knitwear. These defects include pattern defects, casting on or formation of too large stitches, distortion of courses, knitting of stitches of another colour in the jacquard fabric, displacement of pattern repeat, formation of crease marks on the combined interweaving fabric that cannot be eliminated. As a result, in the process of superimposing of the fabric with defects it is necessary to superimpose the layers repeatedly according to the layout of the outline frames so that defects during the knitting come into cuttings.

Press-offs i.e. garment pieces, thread that is not fully knitted due to break, or garment pieces that cannot be processed further due to nonrepairable defects fall within knitting waste as well. The amount of waste due to press-offs is determined based on the repetition and average weight of press-offs. In some cases, press-offs are unravelled and the yarn is reused for knitting. Unravelling of items at small enterprises usually is performed manually. Moreover, after winding the yarn on a package it is required to re-wind the yarn on the winding machine to obtain the package with quality cross-winding, which significantly increases the time of work of a knitter.

In this article it is proposed to recycle the waste of the garment and knitwear industry in the form of press-offs of knitted fabric from flat-knitting machines and use it for knitting of workwear garments (cuffs, collars, belts, etc.). Work in the mining industry is the field of activity, which involves work in unfavourable conditions. Maintenance of heavy mechanisms, increased dust level, gas hazard, humidity - such working conditions force paying special attention to workwear, since a health condition of workers and results of their work in many ways depend on its quality and functionality [12], [13].

Workwear for the mining industry must conform to a range of requirements and modern workwear manufacturers pay great attention to meeting them. Neglect of these requirements would make wear unsuitable and, accordingly, not demanded in the market.

\section{Methodology}

In our work the material balance of production is applied to assess the environmental feasibility of the proposed technology for the use of waste knitwear, as shown in Fig. 1.

For the main production, the balance of recycling is calculated according to the following method:

$$
M_{\mathrm{m} . \mathrm{m}}+M_{\mathrm{a} . \mathrm{m}}=M_{\mathrm{f} . \mathrm{m}}+M_{\mathrm{b} . \mathrm{w}}
$$

where

$M_{\text {m.m }} \quad$ Weight of the main material;

$M_{\text {a.m }} \quad$ Weight of auxiliary material;

$M_{\text {f.m }} \quad$ Weight of finished products;

$M_{\text {b.w }} \quad$ Weight of basic waste. 


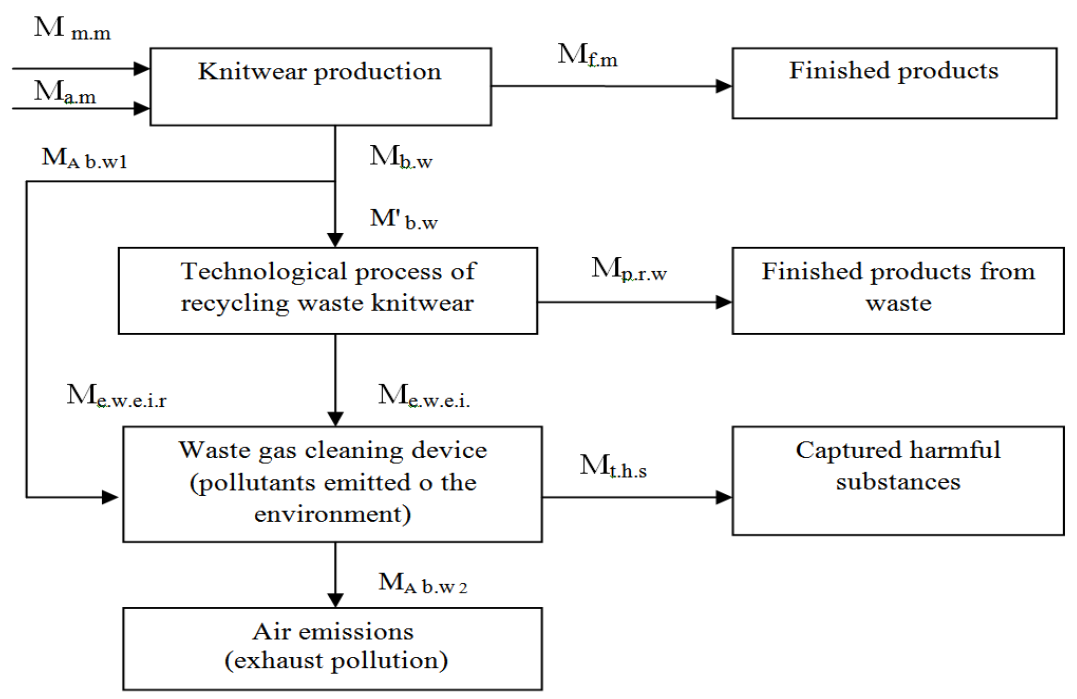

Fig. 1. Scheme of material balance processing waste knitwear production.

The balance of waste processing for the technological process of recycling is calculated as follows:

$$
M_{\text {m.w }}+M_{\text {e.w.e.i.r }}=M_{\text {p.r.w }}+M_{\text {s.w.p.w }},
$$

where

$M_{\text {m.w }} \quad$ Weight of the main wastes;

$M_{\text {e.w.e.i.r }} \quad$ Weight of external waste entering into recycling;

$M_{\text {s.w.p.w }} \quad$ Weight of secondary waste in the processing of waste;

$M_{\text {p.r.w }} \quad$ Finished products from recycled waste.

It follows from Fig. 1 that if we introduce the waste utilization factor $\left(\eta_{\text {main }}\right)$ for the main production, we get:

$$
\begin{gathered}
M^{\prime} \text { b.w }=\eta_{\text {main }} \cdot M_{\mathrm{w}}, \\
M_{\text {w.r.a. } 1}=\left(1-\eta_{\text {main }}\right) \cdot M_{\mathrm{w}},
\end{gathered}
$$

where $M_{\text {w.r.a }}$ is weight of waste released into the atmosphere.

An environmental impact coefficient $\left(K_{\text {e.i.c }}\right)$ is introduced to assess the impact of garment and knitwear production waste emitted into the environment, which is determined according to Eq. (5):

$$
K_{\text {e.i.c }}=M_{\text {n.l.p }} / M_{\text {w.r.a. } 2}
$$

where $M_{\text {n.l.p }}$ is weight of the normalized limit of permissible values of pollutants discharged into the environment.

The utilization rate of waste in general for knitwear production with the technological process of waste processing is calculated by following: 


$$
H_{\text {main }}=M_{\text {p.r.w }} / M_{\text {e.w.e.i.r }}+M_{\text {w }}^{\prime} .
$$

To assess the performance of the garment and knitwear production, the following coefficients are introduced:

$$
\begin{gathered}
K_{\text {c.u }}=N_{\mathrm{a}} / N_{\mathrm{d}}, \\
K_{\text {u.m }}=M_{\text {f.m. }}+M_{\text {p.r.w. }} / M_{\text {m.m }}+M_{\text {a.m }}+M_{\text {e.w.e.i.r }},
\end{gathered}
$$

where

$K_{\text {c.u. }} \quad$ Capacity utilization rate;

$K_{\text {u.m. }} \quad$ Utilization of raw materials;

$N_{\mathrm{a}}, N_{\mathrm{d}} \quad$ Respectively, the actual and design capacity of the production cycle as a whole.

Given the Eq. (3)-(8), we can get the Eq. (9) to assess the environmental feasibility of sewing and knitting:

$$
K=K_{\text {c.u }} \cdot K_{\text {u.m }} \cdot K_{\text {e.i.c }} \cdot K^{\prime}
$$

where

$K^{\curvearrowleft}=M_{\text {t.h.s }} / M_{\text {e.w.e.i.r }} \quad$ Coefficient showing the effectiveness of the processing facilities;

$M_{\text {t.h.s }} \quad$ Weight of trapped harmful substances;

$M_{\text {e.w.e.i.r }} \quad$ Weight of external waste entering into processing.

\section{Results}

\subsection{Developed Technology and Auxiliary Equipment for Recycling}

When processed on the knitting machines and during the service of articles a thread endures the impact of all kinds, which frequently leads to its break and, as a result, deteriorates the quality of yarn. Poor quality yarn has a negative effect not only on the grade of quality of products but also leads to the increased volume of faulty products and production waste. This is also reflected on the performance indicators of an enterprise and the use of equipment [3]-[6].

Within the process of review of dependency of the process of knitting on various factors the reasons of instability of the knitting process have been identified: variability of operating modes of mechanisms securing thread supply, stitch formation and take-down during knitting; irregularity of linear density of yarn; thread tension difference; sinking depth; takedown traction difference; friction, twist, static characteristic and yarn moisture.

Instability of the knitting process affects basic characteristics of the knitwear structure, and therefore the surface density of the knitwear. The surface density of the fabric knitted in any kind of interweaving on a specific machine from specific raw materials is characterized by: linear density of a thread, length of a thread, as well as vertical and horizontal density depending on the length of a stitch and yarn evenness [14].

Yarn evenness is one of the basic quality indicators. Modern processes of spinning and twisting industry are aimed at securing delivery of the most even (homogenous) yarn according to its external structure, thickness, twist, durability. It is impossible to obtain an absolutely even yarn, as within processing of the raw materials deviations in its structure 
occur, which deteriorate the quality of yarn and lead to faults. The evener the yarn and thread, the lower its breakage rate during the knitting, the smaller number of defects and the higher quality of knitted fabric. Unevenness of separate yarn sections also contributes to formation of faulty fabric in the process of knitting. Sections with increased twist cause snarl leading to a thread break and needle breakage in the process of stitch formation. The yarn with increased twist results in incorrect structure of stitches in the fabric (strong distortion of wale), which disfigures the article. The yarn with reduced twist has a higher rate of breakage - and this leads to instability of the knitting process.

When processed on the knitting machines and during the service of articles a thread endures the impact of all kinds, which frequently leads to its break. In the technological processes of production dependence of the rate of a thread break on its linear density unevenness is known [15]. This dependence in turn affects the durability properties of ready products (under stretching), abrasion resistance and shine. Thus, a high quality of yarn is required to obtain even stitch structure and stable surface density of the knitted fabric. These requirements refer also to the reusable yarn.

For solution of the problem in question auxiliary equipment consisting of two devices is proposed for recycling of waste of the garment and knitwear industry [9]: a device for unravelling the items (press-offs) of the knitted outerwear and a device for eliminating the crimping effect of the reusable yarn by means of impact of the water vapour with its subsequent drying [17]-[20].

The proposed auxiliary equipment for recycling of waste of the garment and knitwear industry consists of the following units: a bed, a drive mechanism, a frame with needle cover, a yarn supply apparatus, a steaming and drying mechanism (for elimination of the crimping effect), a mechanism for improving the thread structure.

On the Fig. 2 a process scheme of the developed device for recycling of the knitting waste is presented. The thread is withdrawn from the knitted fabric (press-off of knitting), which is fixed on the frame (1), goes through the thread guide (2), two tensions (3), the control and purifying unit (4). Then the thread undergoes a wet-heat processing and drying going through the chamber (5) and is spooled (6).

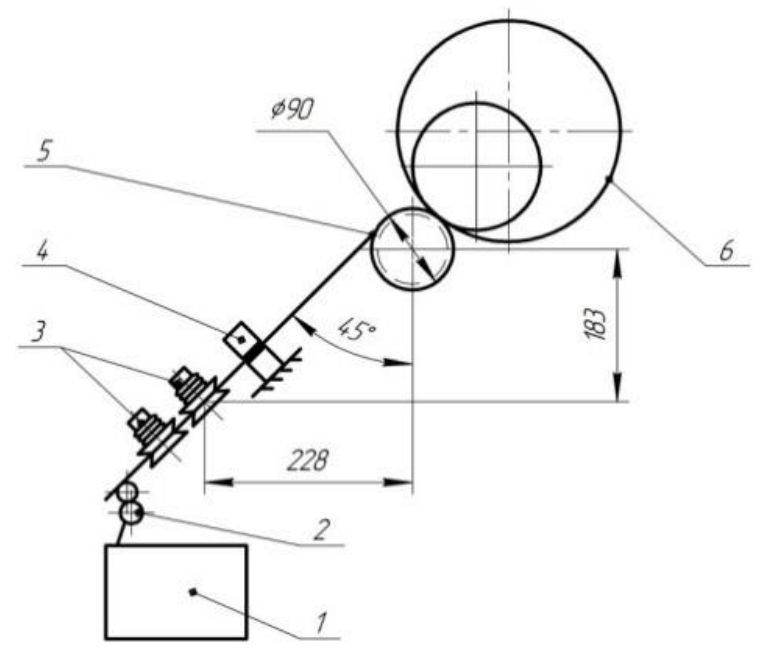

Fig. 2. Process scheme of the developed device. 
The frame represents a flat-topped steelwork with needles (1) located on the top and sides of the fabric (Fig. 3). The rollout side shelf (2), freely shifting in grooves, allows regulating the width of the frame.
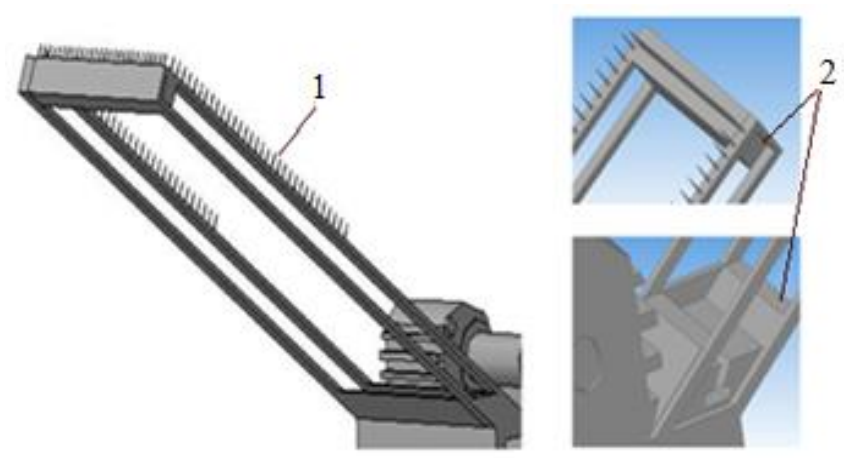

Fig. 3. Model of the frame with a rollout device.

The frame is set up on the body of the device for steaming and subsequent drying of a semi-finished product envisaged for elimination of the crimping effect of the reusable yarn. By analogy to the well-known thermal generating unit the heaters are replaced with an electric heating element located at the bottom of the body for more equal heat supply in the process of yarn drying (Fig. 4).

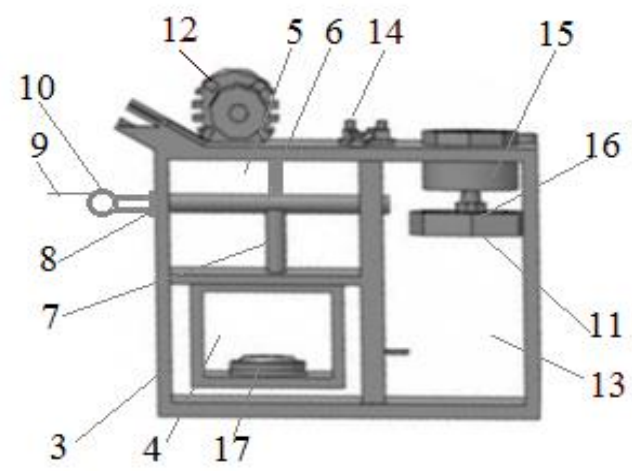

Fig. 4. Model of device for elimination of the crimping effect of the reusable yarn.

Following the unravelling of an unfinished article the yarn retains enough crimp, which leads to uneven thread tension during repeated knitting, deterioration of the fabric structure, decline in the quality of the article appearance. For this reason, it is proposed to process the used thread of the knitted fabric press-off as follows. The thread (9) is threaded through the thread tensioning plates (10), thread guide eyes (8) of the body (3) and comes into the evaporation chamber (5). Water through a pipe (6) is filled into a capacity (4), under which a heating element (17) is located, which brings water to boil. The vapour is delivered to the evaporation chamber (5) through the vapour-removing pipe (7) and impacts the moving thread (9). Following the steam treatment, the thread comes into a drying chamber. With the help of a fan (16) air induction is performed through the air intake (15). When the fan rotates, 
its impeller (11) entraps the air and cools the chamber (13). A damp thread is aired with hot air and goes through the side outlets of the body, thread guide eyes (14) and is spooled on a bobbin operated by an electric motor (12).

In the process of the wet-heat processing on the proposed auxiliary equipment the reusable thread changes its initial qualities under the influence of high temperature and humidity. Hairiness forms on the yarn surface - protruding ends of individual fibres or stitches formed by individual fibres appear. As a consequence, the thread loses its elasticity. Introduction of an oiling device at the stage of spooling a thread allowed reducing its wooliness and remove a glassy state of the processed thread adding elasticity to it. Modernization of the technological equipment allowed for combination in one facility of the unravelling of article items (press-offs) of the knitted outerwear and eliminating the crimping effect of the thread by the wet-heat processing of the semi-manufactured article, to eliminate brushing by means of introducing a thread oiling unit, as well as to ensure quality processing of faulty knitted fabric avoiding its repeated hanging and laying from one facility to another.

When processed on the knitting machines and during the service of articles a thread endures the impact of all kinds, which frequently leads to its break. Dependence of the rate of a thread break in a technological process on its linear density unevenness is known. This in turn affects the durability properties of ready products (stretching if defected), abrasion resistance, shine and other [15].

Based on the conducted analysis it was identified that low-quality yarn negatively affects not only the quality and grade of products but also the enterprise performance figures and the use of equipment. The main factors affecting the quality of yarn were identified - linear density, breaking force and elongation, stability of twist, external defects.

\subsection{Investigation of the Structure and Physic-Mechanical Properties of Reusable Yarn and Knitted Fabrics from it}

For the calculation of the linear thread density the mass and length of thread was preliminarily determined. For this purpose, skeins (leas) with the length of $5 ; 10 ; 25 ; 50 ; 100$; $200 \mathrm{~m}$ depending on the linear thread density were unwinded from the package. Unwinding of the thread into skeins of the required length was performed with the help of an automated device - a reel MPA-1M, which crown perimeter is $1 \mathrm{~m}$ (the crown allows for simultaneous winding of 5 leas). The reel has a special mechanism for automatic stop after winding the thread of the specified length $(25,50$ and $100 \mathrm{~m})$ on the crown. The leas are removed from the reel by the back side of wrists following that the threads do not get tangled.

For determination of the mass of leas weighing textile quadrants were used, which operate without weights according to the equilibrium principle of the three-arm lever.

According to the method the leas with the length of $25 \mathrm{~m}$ were winded from the 3 cone-shaped woollen-thread spools and 3 mixed-thread spools. By cutting the leas the bunches consisting of 25 threads with the length of $1 \mathrm{~m}$ were obtained. 10 cuts were selected from each bunch and were weighed on the torsion balance.

It was determined that the twist also significantly affects the properties of threads. With the increasing intensity of the fibre twist in yarn it is positioned more densely, and the cross-section of the yarn reduces but the volume weight increases. For determination of twist a method of direct untwist was used (it is applied for all types of thread and yarn except for the single cotton one and other from chemical fibre with the linear density above 84 tex). The results are presented in Table 1 and Table 2. 
TABLE 1. TWIST OF EXAMINED TYPES OF YARN

\begin{tabular}{lllll}
\hline Type of yarn & $\begin{array}{l}\text { Twist coefficient value } \\
\text { according to GOST 6611-3-73 }\end{array}$ & $\begin{array}{l}\text { Average } \\
\text { value }\end{array}$ & $\begin{array}{l}\text { Coefficient of } \\
\text { variation, } \%\end{array}$ & $\begin{array}{l}\text { Deviations from the twist } \\
\text { coefficient according to } \\
\text { GOST 6611-3-73 }\end{array}$ \\
\hline Before WHP & & & & \\
\hline Woollen & 15 & 15.7 & 2.5 & \pm 6 \\
Mixed & 15 & 14.8 & 7.57 & \pm 6 \\
\hline After WHP & & & & \pm 6 \\
\hline Woollen & 15 & 14.02 & 2.0 & \pm 6 \\
Mixed & 15 & 14.0 & 3.37 & \pm 6 \\
\hline
\end{tabular}

TABLE 2. LINEAR DENSITY OF EXAMINED TYPES OF YARN

\begin{tabular}{llll}
\hline Type of yarn & $\begin{array}{l}\text { Average value of } \\
\text { linear density, tex }\end{array}$ & $\begin{array}{l}\text { Standard } \\
\text { deviation }\end{array}$ & $\begin{array}{l}\text { Coefficient of } \\
\text { variation, } \%\end{array}$ \\
\hline Before WHP & & & \\
\hline Woollen & 59.05 & 1.14 & 2.2 \\
Mixed & 59.3 & 1.64 & 4.5 \\
\hline After WHP & & & \\
\hline Woollen & 64.4 & 1.17 & 2.14 \\
Mixed & 59.8 & 1.24 & 2.58 \\
\hline
\end{tabular}

The analysis of research of the impact of the wet-heat processing (hereinafter - WHP) on the physical and mechanical and geometrical yarn properties was conducted. It was found that under the high humidity the wool fibre does not act as a homogeneous and transversely isotropic body but rather as a heterogeneous anisotropic body. The difference is in the rate of reduction of the Young's modulus and shear modulus with humidity increase. It can be explained by the fact that absorption of water by keratin leads to a significantly bigger number of breaks of hydrogen bonds in diameter of the fibre than longwise.

At the simultaneous impact of humidity and heat in the wool keratin the hydrolysis of disulphide intermolecular bonds takes place which leads to the durability loss of the wool fibre and its increased deformability. If the impact of humidity and heat is comparatively short, i.e. during drying and cooling, the disulphide bonds restore, which enables stable fixation of the fibre deformation.

Analysis of the obtained data showed that the linear density of all types of yarn increases following the WHP, which conforms to the value within the standard. Decrease in the coefficient of variation following the WHP indicates the homogeneity of yarn thickness which positively affects the stability of the knitting process. The value of the twist indicator following the WHP reduced for all types of yarn within the standards allowed by GOST. The actual moisture of all types of yarn following the WHP increased to the value close to the maximum allowed one. Increase in the durability of woollen yarn was identified - by $6.25 \%$, of mixed yarn - by $16 \%$, as well as a lack of crimping effect for all types of yarn. However, the process of WHP caused insignificant shrinkage of yarn: by $2.5 \%$ of the woollen yarn and by $2.1 \%$ of the mixed yarn.

When processed on the knitting machines and during the service of articles a thread endures the impact of all kinds, which may lead to its break. Therefore, for characteristics of the capability of textile threads to perceive stretching force without breaks the indicators of 
breaking force and breaking elongation are introduced. In the technological processes of production dependence of the rate of a thread break on its linear density unevenness is known, which in turn affects the durability properties of ready products (stretching if defected), abrasion resistance, shine and other.

It is proposed to use mixed knitted fabrics for production of workwear garments [21]-[23]. Especially efficient is the quality of fabrics from the mixture of synthetical and natural threads (wool, cotton).

It was established that the physical and mechanical properties of the woollenfibre significantly depend on the volume of moisture of absorbed wool. Activity of the intermolecular adhesive force, as well as of attractive forces of active centres along the main chains shaping them into spirals manifest most fully in the absence of humidity. The woollenfibre has the maximum durability and minimum elongation in an absolutely dry condition. Intermolecular and intramolecular adhesive force, if not hindered by the presence of water molecules, prevent from activity of deformation forces with greater power. Hydration of these groups takes place, as a result the effect of mutual attractive forces weakens.

Reduction of durability and increase of elongation within stretching of the woollenfibre depends on the amount of absorbed humidity. Absolutely dry fibre can be hardly ever stretched over 20-25\%, while in water or in the atmosphere rich in water vapour under a usual temperature the stretching of around $70 \%$ of the initial length can be reached.

Reduction of durability and increase of elongation within stretching of the woollen fibre depends on the amount of absorbed humidity. Absolutely dry fibre can be hardly ever stretched over 20-25\%, while in the water or in the atmosphere rich in water vapour under a usual temperature the stretching of around $70 \%$ of the initial length can be reached. On the Fig. 5 stretching bars of woollen fibres with different moisture level are given.

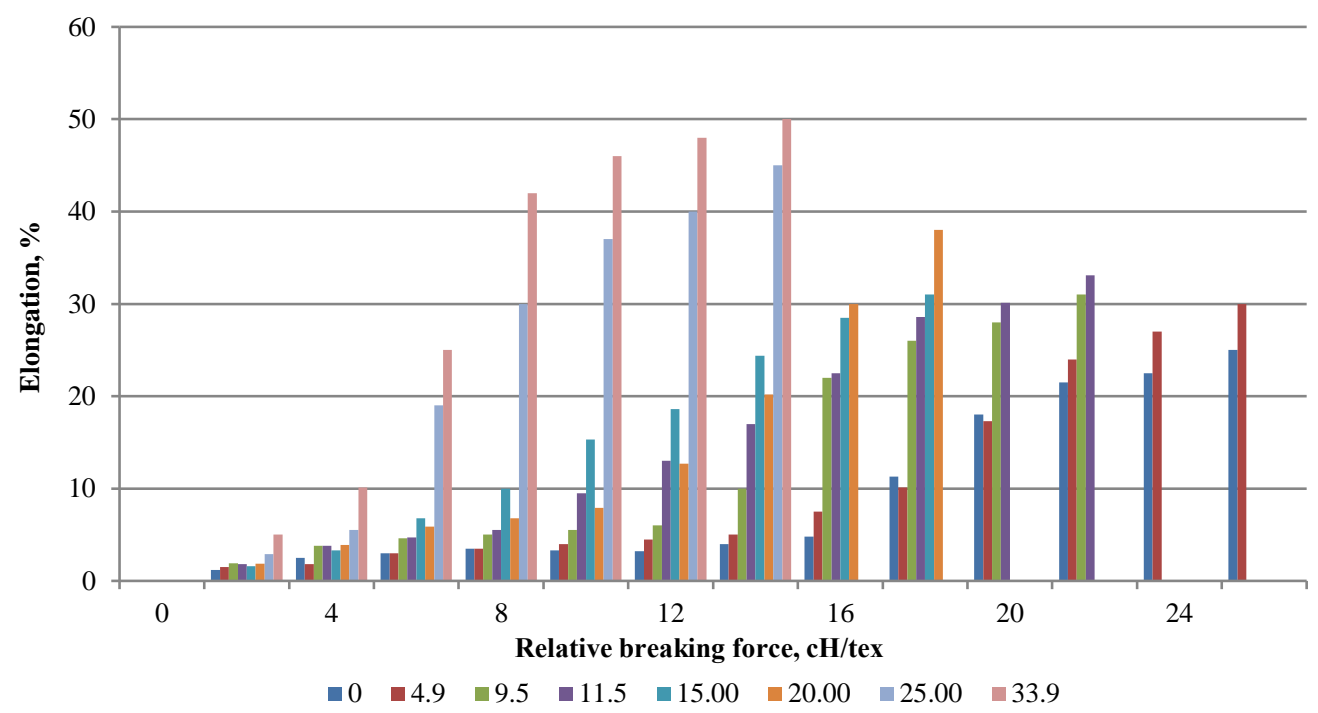

Fig. 5. Histogram of stretching of wool fibres at their different moisture content.

According to the research, the breaking durability of wool in water reduces by $10 \%$, the breaking elongation increases approximately 1.5 times. The effect of humidity has a profound impact on the speed of relaxation processes in case of strain. If the stretched 
woolenfibre is absolutely dry, it does not show any tendency towards reverse shrinkage (except for true resilient shrinkage), i.e. the time of relaxation of the highly elastic strain is so great that it is nearly irreversible. Strain relaxation under standard atmospheric conditions takes place much faster but slowly at the same time. The speed of shrinkage of the stretched fibre naturally increases with the increasing relative humidity of the environment.

Two types of yarn were chosen as objects of study: wool mixed with a linear density of 31 tex 2 . In order to remove the crimp of yarn and the impact of the WTO yarn on the above indicators. The work was carried out in 3 versions:

- Of the initial yarn which was not exposed to WHP;

- Crimp yarn after unravelling and exposed to WHP at the steaming-drying device, immediately following the processing;

- Crimp yarn after unravelling and exposed to steam treatment and oiling with emulsion, immediately following the processing.

During the research the mass, diameter, linear density, relative breaking force, twist coefficient and moisture of the selected thread samples from 10 batches with the length of $10 \mathrm{~m}$ were measured. With the help of correlational analysis dependencies between the values before and after processing of threads by WHP were found. The impact was made by water vapour and emulsion. The results of measurements are presented in Tables 3-5.

In order to determine the conformity of properties of knitted fabrics knitted from the recycled yarn to standard values, knitted articles were knitted from all samples of yarn in question. In the process of determination of the surface density according to GOST 8845-66 10 samples of knitted fabrics knitted at machines of class 8 of PVK type according to a stockinette structure from pure-wool and mixed yarn with the linear density of 31 tex 22 were selected, before and after WHP and the drying process following the steam treatment, i.e. in the drying device. The surface density was determined according to GOST-8845-68. The obtained experimental findings were mathematically processed and compiled in Tables 3-5.

TABLE 3. Determination of ACTUAL MoISTURE OF YARn, Which WAS NOT EXPOSED to WHP

\begin{tabular}{llllllll}
\hline \multirow{2}{*}{ Type of yarn } & $\begin{array}{l}\text { No. of } \\
\text { sample }\end{array}$ & \multicolumn{3}{c}{ Mass of sample, $\mathrm{g}$} & \multicolumn{3}{c}{ Moisture, \% } \\
\cline { 3 - 8 } & $\mathrm{m} 1$ & $\mathrm{~m} 2$ & $\mathrm{~m} 3$ & $\mathrm{~m} 4$ & Actual & Average \\
\hline Woollen & 1 & 9.8 & 8.9 & 8.5 & 8.4 & 15.67 & \\
31 tex 2 & 2 & 9.6 & 8.8 & 8.4 & 8.3 & 15.66 & 16.17 \\
\hline Mixed & 1 & 9.4 & 9.0 & 8.7 & 8.6 & 9.3 & \\
31 tex 2 & 2 & 9.3 & 8.9 & 8.6 & 8.5 & 9.4 & 9.36 \\
\hline
\end{tabular}

TABle 4. DETERMINATION OF ACTUAL MoISTURE OF CRIMP YARn Following THE UNRAVELLING, WHICH WAS EXPOSED TO WHP

\begin{tabular}{|c|c|c|c|c|c|c|c|c|c|c|c|c|c|}
\hline \multirow[t]{3}{*}{ Type of yarn } & \multirow{3}{*}{ 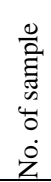 } & \multicolumn{8}{|c|}{ Mass of sample, $g$} & \multicolumn{4}{|c|}{ Moisture, \% } \\
\hline & & \multicolumn{4}{|c|}{ Immediately after WHP } & \multicolumn{4}{|c|}{$\begin{array}{l}\text { In } 24 \mathrm{~h} \text { following the } \\
\text { processing }\end{array}$} & \multicolumn{2}{|c|}{$\begin{array}{l}\text { Immediately } \\
\text { after WHP }\end{array}$} & \multicolumn{2}{|c|}{ In $24 \mathrm{~h}$ after WHP } \\
\hline & & $\mathrm{m} 1$ & $\mathrm{~m} 2$ & $\mathrm{~m} 3$ & $\mathrm{~m} 4$ & $\mathrm{~m} 1$ & $\mathrm{~m} 2$ & $\mathrm{~m} 3$ & $\mathrm{~m} 4$ & Actual & Average & Actual & Average \\
\hline Woollen & 1 & 10 & 9.1 & 8.6 & 8.5 & 9.8 & 9.0 & 8.5 & 8.4 & 17.65 & & 16.67 & \\
\hline 31 tex $\cdot 2$ & 2 & 9.8 & 9.0 & 8.7 & 8.3 & 9.7 & 8.8 & 8.3 & 8.2 & 18.07 & 17.86 & 18.29 & 17.48 \\
\hline Mixed & 1 & 9.6 & 9.1 & 8.8 & 8.7 & 9.5 & 9.0 & 8.7 & 8.6 & 10.3 & & 10.5 & \\
\hline 31 tex $\cdot 2$ & 2 & 9.4 & 8.8 & 8.6 & 8.5 & 9.4 & 8.9 & 8.6 & 8.5 & 10.6 & 10.45 & 9.4 & 9.93 \\
\hline
\end{tabular}


TABLE 5. DETERMINATION OF ACTUAL MOISTURE OF CRIMP YARN FOLLOWING THE UNRAVELLING, WHICH WAS EXPOSED TO STEAM TREATMENT

\begin{tabular}{|c|c|c|c|c|c|c|c|c|c|c|c|c|c|}
\hline \multirow[t]{3}{*}{ Type of yarn } & \multirow{3}{*}{ 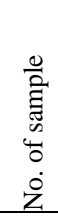 } & \multicolumn{8}{|c|}{ Mass of sample, $\mathrm{g}$} & \multicolumn{4}{|c|}{ Moisture, \% } \\
\hline & & \multicolumn{4}{|c|}{ Immediately after WHP } & \multicolumn{4}{|c|}{$\begin{array}{l}\text { In } 24 \mathrm{~h} \text { following the } \\
\text { processing }\end{array}$} & \multicolumn{2}{|c|}{$\begin{array}{l}\text { Immediately } \\
\text { after the } \\
\text { processing }\end{array}$} & \multicolumn{2}{|c|}{$\begin{array}{l}\text { In } 24 \mathrm{~h} \\
\text { following the } \\
\text { processing }\end{array}$} \\
\hline & & $\mathrm{m} 1$ & $\mathrm{~m} 2$ & $\mathrm{~m} 3$ & $\mathrm{~m} 4$ & $\mathrm{~m} 1$ & $\mathrm{~m} 2$ & $\mathrm{~m} 3$ & $\mathrm{~m} 4$ & Actual & Average & Actual & Average \\
\hline \multirow{2}{*}{$\begin{array}{l}\text { Woollen } 31 \\
\text { tex } 2\end{array}$} & 1 & 12.1 & 11 & 10.1 & 10 & 11.2 & 9.9 & 9.4 & 9.3 & 21 & \multirow[t]{2}{*}{20.4} & 20.4 & \multirow[t]{2}{*}{19.54} \\
\hline & 2 & 11.5 & 10.4 & 9.7 & 9.6 & 10.8 & 9.8 & 9.2 & 9.1 & 19.8 & & 18.68 & \\
\hline Mixed & 1 & 10.7 & 10 & 9.7 & 9.6 & 10.5 & 9.9 & 9.6 & 9.5 & 11.45 & & 10.53 & \\
\hline 31 tex $\cdot 2$ & 2 & 10.4 & 9.7 & 9.4 & 9.3 & 10.2 & 9.6 & 9.3 & 9.2 & 11.83 & 11.64 & 10.87 & 10.7 \\
\hline
\end{tabular}

The obtained experimental findings were mathematically processed and compiled in Table 6 and Table 7.

TABle 6. Surface Density OF THE FABRIC BEFORE WHP AND AFTER WHP

\begin{tabular}{lllll}
\hline Yarn & $\begin{array}{l}\text { Linear density } \\
\text { of yarn, tex }\end{array}$ & $\begin{array}{l}\text { Average } \\
\text { values }\end{array}$ & $\begin{array}{l}\text { Deviations } \\
\text { allowed by the standard }\end{array}$ & $\begin{array}{l}\text { Variation } \\
\text { coefficient }\end{array}$ \\
\hline Before WHP (woollen) & 31 tex $\cdot 2 \cdot 2$ & 372.6 & 7.88 & 2.11 \\
After WHP (woollen) & 31 tex 22 & 364.2 & 7.76 & 2.03 \\
Before WHP (mixed) & 31 tex $\cdot 2 \cdot 2$ & 366.6 & 8.14 & 2.22 \\
After WHP (mixed) & 31 tex $\cdot 2 \cdot 2$ & 342.3 & 5.19 & 1.51 \\
\hline
\end{tabular}

Instability of the knitting process, as already noted above, affects the basic characteristics of the knitting structure, and thus the surface density of the knitting. It is known that the mass of nontreated knitted fabric depends on the type of raw materials, the type of interweaving, length of a stitch, linear density of a thread, horizontal and vertical density, a class of machine. The surface density of the fabric knitted in any kind of interweaving on a specific machine from specific raw materials is determined by: linear density of a thread, length of a stitch, vertical and horizontal density, which in turn depend on the leng th of a stitch. In the earlier research it was found that the basic factors affecting the length of a stitch are: sinking depth; entry thread tension, fabric take-down traction, linear density of a thread, as well as its properties such as frictional ability, rigidity, stretchability, twist, etc., which are permanent for each type of a thread.

In Table 7 characteristics of the fabrics in question are provided.

It is seen from the Table 6 that the surface density of the structure from pure-wool yarn after WHP reduced compared to the actual one by $8.5 \mathrm{~g}(3.3 \%)$ and approached standard values, after the drying it reduced by $5.2 \mathrm{~g}$ and deviated from the standard value by 11 grams $(2.7 \%)$. 
TABle 7. CharaCteristics of the FABRiCs From the MACHINES OF ClaSs 8 OF PVK TYPE

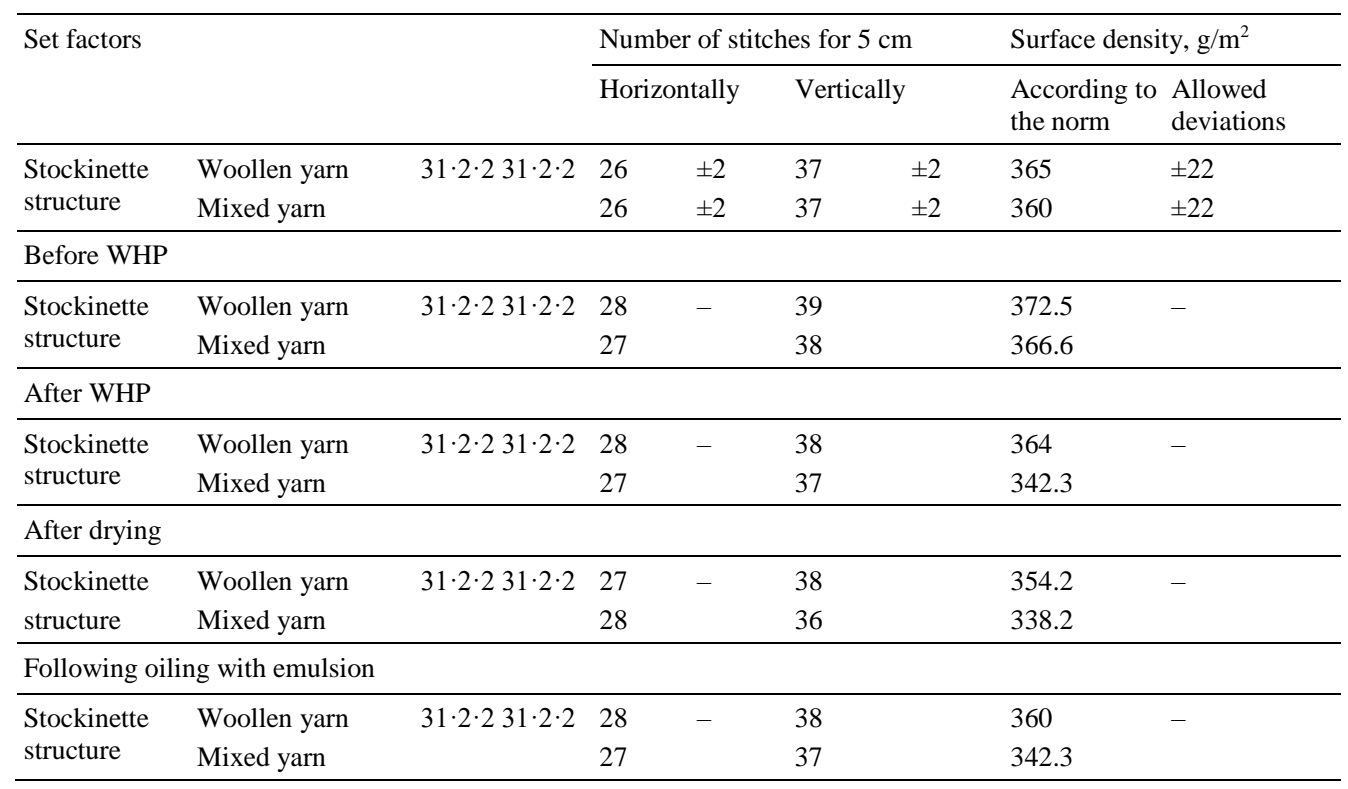

The charts of distribution of surface density of the fabric from pure-wool and mixed yarn are depicted in Fig. 6 and Fig. 7.

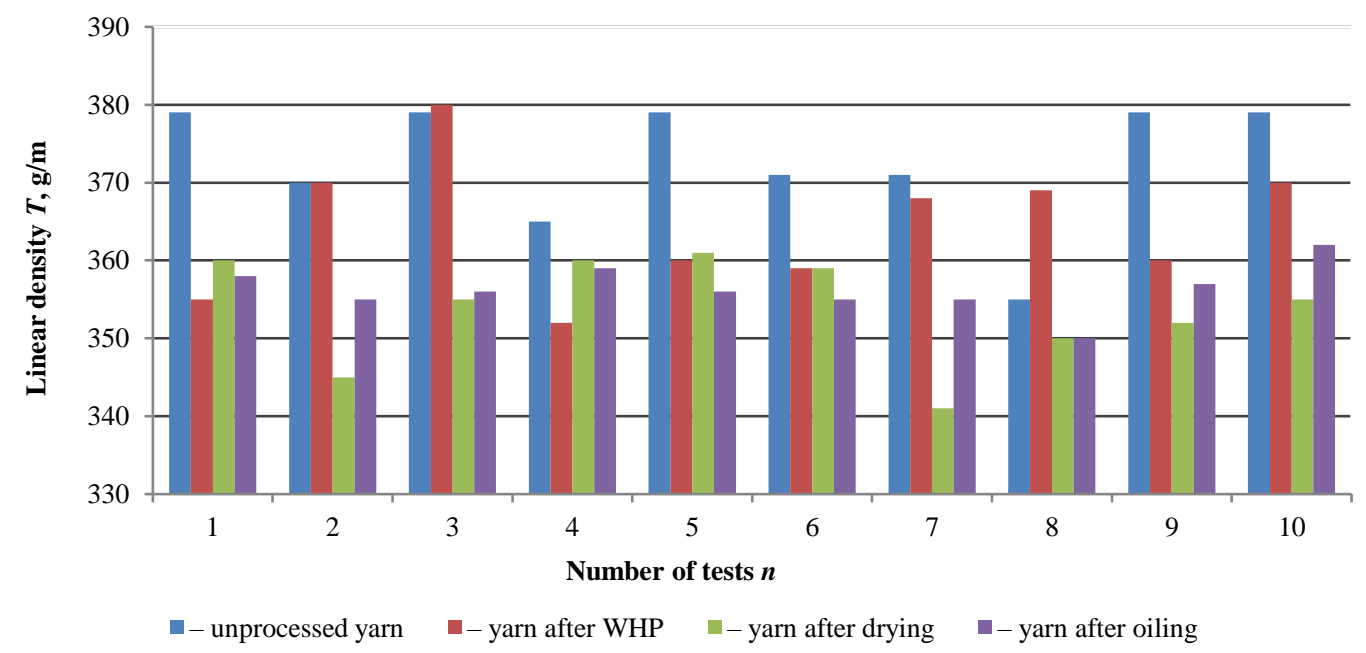

Fig. 6. The influence of WTO pure wool yarn on the surface density of the weave curly weave.

The results of the research are clearly seen in the charts of distribution of the surface density of the fabric from pure-wool and mixed yarn. According to the analysis of the results, the surface density of the yarn after WHP reduced by $24.32-6.63 \%$ but remained within the allowed deviations from the standard. After drying the surface density of the knitted fabric reduced compared to the actual one by $7.6 \%$ but remained within the allowed deviation from GOST. 


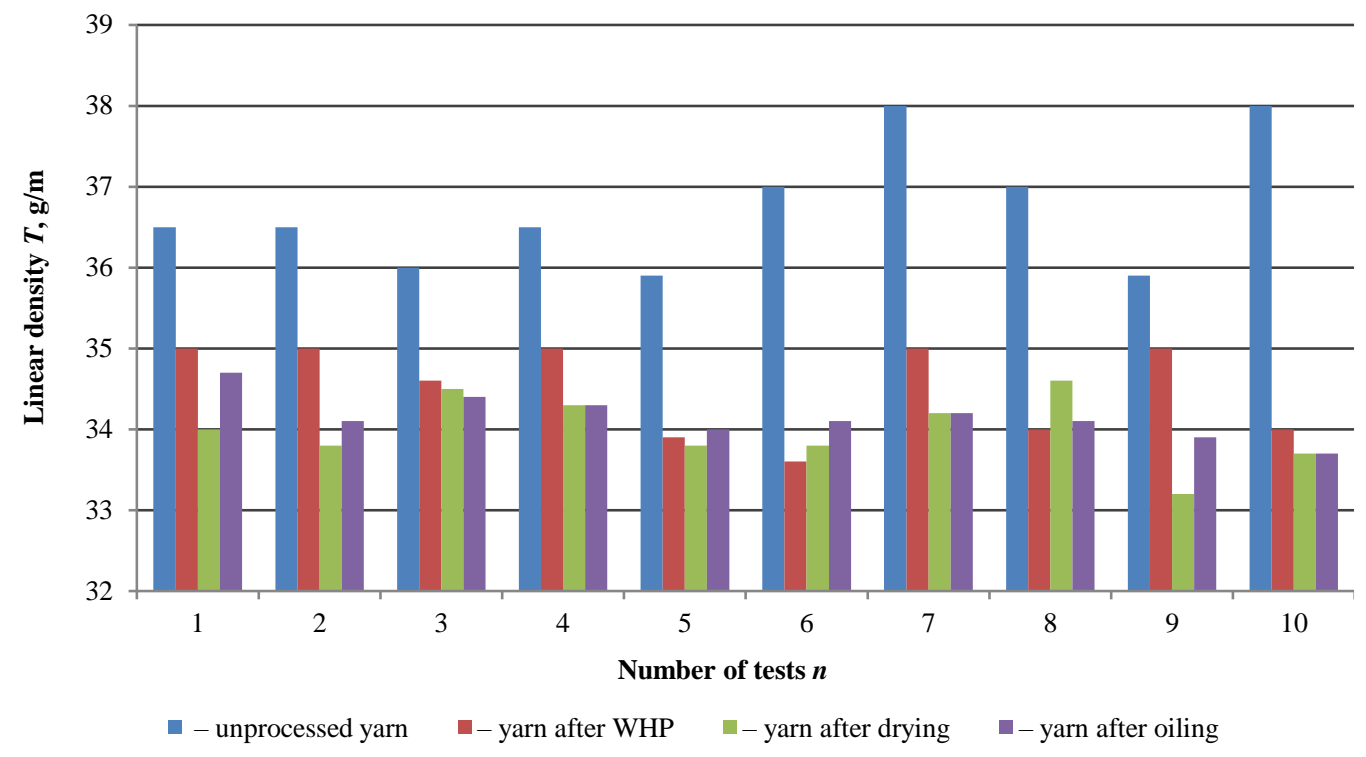

Fig. 7. The effect of mixed WTO yarn on the surface density of the weave curly cloth.

The surface density of yarn following the oiling with special emulsion solution increased and almost returned to the values after WHP. The use of the wet-heat processing for removing the crimping effect and further oiling with special emulsion provides an opportunity to obtain more stable knitted fabrics from the recycled yarn. Hence, the proposed technology not only provides an opportunity to reuse the yarn for manufacturing of articles but also returns to the thread the properties that are close to the initial ones. The obtained articles from the recycled thread conform to the quality standards.

In the work in the process of studying the impact of the wet-heat processing of yarn on the surface density of the fabric from the recycled thread the following results were obtained:

- It was determined that within the processing of mixed yarn with the summary coefficient of variation of thickness $3.5 \%$ and variation of the take-down traction of the fabric up to $35 \%$, instability of the surface density may comprise $8.5 \%, 4 \%$ of which will occur only due to the unevenness of thread thickness. Therefore, an important condition for increasing the stability of the mass of the knitted fabric is application of yarn and thread with the minimum possible coefficient of variation in its linear density;

- Unevenness of the recycled thread in its linear density affects the increase of instability of the mass of the fabric to a significantly larger extent than the process of formation of the fabric. As a result of irregularity of the equipment operation the share of overall unevenness of the knitted fabric comprised $7.5 \%$ but $92.5 \%$ refer to the unevenness of the thread;

- Increase of the power of tangential resistance of the fibre occurring as a result of condensation of the mass of the fibre in the process of twisting and oiling enables obtaining evener yarn. Simultaneously, the yarn durability and other properties depend on the level (intensity) of twist. The bigger the size of twist and thread thickness, the bigger the twist take-up of a thread, and the bigger the exposure to tension of the thread in the process of twisting, the less the twist take-up of a thread; 
- As a result of flat twist, the thread is not so strong but is softer, as a result of high twist - strong and coarse. Under the radial stress occurring in the process of twist the fibres compress tighter, the diameter of the thread decreases, the fibre friction grows, the length of fibre spinning increases and at the same time the yarn durability improves. Increase in the coefficient of twist and twisting ankle increase the durability of yarn to a definite limit (critical twist). Further twist leads to fall of the thread durability due to excessive strain of the fibres stretched by twist. The breaking force of yarn increases with the increase of twist;

- The actual moisture of all types of yarn following the wet-heat processing increased and approached standard values. The twist decreased but remained within the values permitted by the standards, but the yarn durability increased: of the woollen yarn by $6.25 \%$, of the mixed yarn - by $16 \%$. The crimp of yarn of all types disappeared completely. Following the wet-heat processing insignificant shrinkage occurred: by $2.5 \%$ of the woollen yarn and by $2.1 \%$ of the mixed yarn;

- The results obtained following processing with the water vapour and emulsion are higher and the link between the indicators is closer than following the wet-heat processing.

Thus, the research confirms conformity of the linear density indicators of the fabric from the recycled thread to standard indicators of the linear density of the fabric made from a primary thread. The obtained fabrics are equal in quality and functionality, on which a health condition of workers and results of their work depend, and comply with the GOST requirements.

\section{Discussion}

The environmental feasibility of the technology of using waste of the garment and knitwear industry showed that the processes of recycling waste of the garment and knitwear industry, namely of shredding (cutting) operations and garneting of waste should be considered from the position of a single technological cycle, i.e. from the position of technical-environmental and environmental-economic assessment [24], [25].

Analysis of the work of modern garment and knitwear production shows that production operates environmentally efficiently with coefficient values greater than 0.75 , and with values less than 0.4 , production in ecological and technological terms is not effective.

Baseline data for assessing the environmental feasibility of the developed technology for the use of garment and knitwear production waste are presented in Table 8, and the calculation results are in Table 9. 
TABLE 8. DATA FOR ASSESSING THE ENVIRONMENTAL FEASIBILITY OF THE DEVELOPED TECHNOLOGY FOR THE USE OF GARMENT AND KNITWEAR WASTE

\begin{tabular}{|c|c|c|c|}
\hline \multirow{2}{*}{ Indicators } & \multirow{2}{*}{ Units } & \multicolumn{2}{|c|}{ Meanings } \\
\hline & & Existing & Developed \\
\hline \multicolumn{4}{|l|}{ Volume of products: } \\
\hline - $\quad$ according to the project $M_{\mathrm{p}}$ & pcs/hour & 90 & 90 \\
\hline$-\quad$ in fact $M_{\mathrm{f}}$ & pes/hour & 83 & 83 \\
\hline Consumption of the main raw materials & kg/per prod.un. & 0.67 & 0.67 \\
\hline$M_{\mathrm{m} . \mathrm{m}}$ - weight of the main material & tonnes/year & 2271.7 & 2271.7 \\
\hline$M_{\mathrm{a} . \mathrm{m}}-$ weight of auxiliary material & tonnes/year & 1544 & 1544 \\
\hline$M_{\text {f.p }}-$ weight of finished product & tonnes/year & 2912.9 & 2912.9 \\
\hline$M_{\text {b.w }}-$ waste weight & tonnes/year & 903 & 458 \\
\hline Total waste: & t/hour & 0.43 & 0.43 \\
\hline _ used waste volume & t/hour & 0.132 & 0.179 \\
\hline _ trash and dust & t/hour & 0.133 & 0.133 \\
\hline - unused waste & t/hour & 0.075 & 0.025 \\
\hline $\begin{array}{l}\text { The total mass of waste emitted into the } \\
\text { environment }\end{array}$ & t/hour & 0.152 & 0.100 \\
\hline
\end{tabular}

TABLE 9. CALCUlation the ASSESSMENT OF THE

ENVIRONMENTAL FEASIBILITY OF THE DEVELOPED METHODS AND Devices for the Use of Waste SEWING AND KNitTing Production

\begin{tabular}{lll}
\hline Indicators & $\begin{array}{l}\text { Meaning } \\
\text { Existing }\end{array}$ & Developed \\
\hline Capacity utilization rate, $K_{\text {c.u. }}$ & 0.97 & 0.97 \\
Raw material utilization rate, $K_{\text {u.m. }}$ & 0.68 & 0.85 \\
Coefficient of environmental impact, $K_{\text {c.e.i }}$ & 0.14 & 0.184 \\
$\begin{array}{l}\text { Waste utilization rate, } \eta_{\text {main }} \\
\begin{array}{l}\text { The efficiency ratio of the sewing and knitting } \\
\text { production }\end{array}\end{array}$ & 0.38 & 0.53 \\
$\begin{array}{l}\text { The coefficient of ecological feasibility of } \\
\text { garment and knitwear production with the } \\
\text { technological process of waste processing, } K\end{array}$ & 0.45 & 0.88 \\
\hline
\end{tabular}

As follows from Table 9, the coefficients characterizing the technical and environmental levels of production functioning are two times higher than within existing technology when using the developed technology in the garment and knitwear industry.

For example, the range of articles of the Kostanau Spinning and Knitting Factory with the use of the production waste is very diverse. Basically, the waste at the factory is recycled into nonwoven fabric of different purpose or into products having simpler manufacturing technology in the form of oakum, upholstery batting and technical cotton-wool, cleaning ends, etc.

Approximately 903 t of waste is produced by the Kostanau Spinning and Knitting Factory annually only in the cloth-cutting and garment manufacturing. 
TABLE 10. WASTE AND REFUSE OF KSKF AND THEIR USE, KG

\begin{tabular}{lllllll}
\hline $\begin{array}{l}\text { Name of } \\
\text { enterprise }\end{array}$ & $\begin{array}{l}\text { Cloth-cutting } \\
\text { and garment }\end{array}$ & $\begin{array}{l}\text { Winding and } \\
\text { knitting }\end{array}$ & Total refuse & Stocking & \multicolumn{2}{c}{$\begin{array}{c}\text { Used at the enterprise in total } \\
\text { kg }\end{array}$} \\
\hline KSKF & 903000 & 113595 & 57400.0 & 180643 & 739604 & 75 \\
\hline
\end{tabular}

It is seen from the Table 10 that out of the total volume of waste $-75 \%$ is recycled in the own production, $515034 \mathrm{~kg}$ of waste - taken to the dump, this is refuse of a vegetable origin in the form of sweepings of the pure-wool and mixed yarn (yarn with other fibre), raising flocks from cotton, mixed and woollenfibres, cleaning rags from different size of rags (dirty, oily).

Quantity and quality indicators of the use of waste of the garment and knitwear industry were calculated. The quality indicators are changes of the performance indicators of waste per one end product unit, with current year's waste compared to the previous year's indicators, as well as the circularity indicator [26], [27].

The circularity indicator of the use of waste according to:

$$
B_{i}=\frac{V_{i}-V_{i}^{\prime}}{V_{i}}
$$

where $V_{i}, V_{i}^{\prime}$ are amount of raw materials of $i$ type (class), accordingly used for manufacturing of products.

It is proposed to use the methods and devices for recycling of the garment and knitwear industry waste for the reuse of waste.

Then the Eq. (8) will be as follows:

$$
B_{i}=\frac{V_{i}-V_{i}^{\prime}}{V_{i}}+\frac{V_{i}^{\prime}-V_{i}^{\prime \prime}}{V_{i}},
$$

where $V_{i}^{\prime \prime}$ is amount of raw materials of $i$ type (class), going to the non-used waste.

Here the second addend of the Eq. (8) shows the share of the reusable raw materials (raw materials recovered from the waste components).

According to the Eq. (8), the quality indicator of waste handling using KSKF as an example was calculated. The results are presented in Table 11.

TABLE 11. QUALITY INDICATORS OF WASTE HANDLING, \%

\begin{tabular}{lllll}
\hline Name of technology & \multicolumn{2}{l}{ Coefficient of circularity B } & Difference \\
& Primary & $\begin{array}{l}\text { Following the } \\
\text { reuse }\end{array}$ & Generalized & \\
\hline Existing technology & 75.0 & - & 75.0 & 15 \\
Developed technology & 75.0 & 15 & 90.0 & - \\
\hline
\end{tabular}


According to the Table 11, the circularity indicator in introducing the developed technology is by $15 \%$ higher than in the current operational regime of the Kostanau Spinning and Knitting Factory.

Under the current operational regime, the Kostanau Spinning and Knitting Factory produces up to $25 \%$ of waste but recovery of the cloth-cutting and garment waste and winding and knitting waste is performed partially. As a result of introduction of the developed technology the circularity indicator of the use of waste compared to the current operational regime of the factory increased by $15 \%$.

\section{Conclusions}

The waste handling management system in the garment and knitwear industry is practically not implemented. According to ISO 14000-96, the waste management system offers introduction of the system of measurements and examinations, as well as awareness and training of workers in the issues of engineering ecology. The analysis of work of the modern garment and knitwear industry showed that the production operates environmentally efficiently under the coefficient values $\mathrm{K}>0.75$, under the values of $\mathrm{K}<0.4$ the production in the environmental and technological terms is inefficient. The results of the calculations showed that in using the developed methods and devices in the garment and knitwear industry the coefficients characterizing the technical and environmental levels of functioning of the production are two times higher than under the current technology.

The value of the work is in the fact that introduction into production of the universal auxiliary equipment for recycling of waste of the garment and knitwear industry will enable obtaining workwear garments (cuffs, collars, belts, etc.) from the recycled thread, which quality and functionality is equal to the garments made from new yarn according to GOST.

Thus, the obtained fabric, which combines quality and economic efficiency at the same time, may be used in production of new articles but introduction of the improved device into the production will enable rectifying productional errors and implementing a zero-waste technology.

\section{REFERENCES}

[1] Stas G. V., Sarichev V. I., Pushkarev A. E. Providing Safety When Mineral Field Development by Open-Cut Method. IzvestiyaTulGU. Natural sciences 2012:1(2):188-198. (in Russian).

[2] Mihailova V. N., Yushkova O. I. Opredelenie rabotosposobnosti cheloveka v teplozaschitnoi specodezhde. Mining Informational and Analytical Bulletin. Scientific and Technical Journal 2011:7:155-167. (in Russian).

[3] Radchenko O. V., Makeev N. N., Veselov V. V. Sposob obrabotki prjazhi i nitej. R.F. Patent 2128740. Apr. 10, 1999.

[4] Batishheva N. A., Veselov V. V., Batishhev A. E., Veselov O. V. Sposob obrabotki prjazhi i nitej. R.F. Patent 2010054 C1. Mar. 30, 1994.

[5] Kadnikova O. Y., Altynbayeva G. K., Aidarkhanov A. M., Shaldykova B. A., Uspanova S. S. Waste recycling in sewing and knitting production. Izvestiya Vysshikh Uchebnykh Zavedenii, Seriya Teknologiya Tekstilnoi Promyshlennosti 2016:5:141-143. (in Russian).

[6] Gallucci G. Method for trimming clothing articles e.g. hosiery constituted by paired unit of materials, involves deactivating aspirating unit and following removal of article from operating plane by using control board. Patent WO2013124812A1 IT1409647-B EP2817128-A1. 2015.

[7] Priedniece V., Spalvins K., Ivanovs K. Bioproducts from Potatoes. A Review. Environmental and Climate Technologies 2017:21(1):18-27. doi:10.1515/rtuect-2017-0013

[8] Spalvins K., Blumberga D. Production of Fish Feed and Fish Oil from Waste Biomass Using Microorganisms: Overview of Methods Analyzing Resource Availability. Environmental and Climate Technologies 2018:22(1):149-164 doi:10.2478/rtuect-2018-0010

[9] Vaczl A. Modern processing of waste knitwear. Textile Industry 2008:5:32-35. 
[10] Azimov, Sh. G. Analysis of the features of knitted fabrics and the use of their waste in the production of garments and knitwear. Young Scientist 2015:9:139-142.

[11] Imankulova A. S., Moldokanova A. I. Study of textile and sewing waste at the enterprises of Bishkek. Textile industry 2012:5:26-27.

[12] Kittipongvises S. Assessment of Environmental Impacts of Limestone Quarrying Operations in Thailand. Environmental and Climate Technologies 2017:20(1):67-83. doi:10.1515/rtuect-2017-0011

[13] Sutthichaimethee P., Sawangdee Y. Model of Environmental Problems Priority Arising from the use of Environmental and Natural Resources in Machinery Sectors of Thailand. Environmental and Climate Technologies 2016:17(1):18-29. doi:10.1515/rtuect-2016-0003

[14] Ismail Z. Z., Talib A. R. Recycled medical cotton industry waste as a source of biogas recovery. Journal of Cleaner Production 2016:112(5):4413-4418. doi:10.1016/j.jclepro.2015.06.069

[15] Kadnikova O. Y., Altynbayeva G. K., Kuzmin S., Aidarkhanov A. M., Shaldykova B. A. Recycling of production waste as a way to improve environmental conditions. Energy Procedia 2018:147:402-408. doi:10.1016/j.egypro.2018.07.110

[16] Kadnikova O. Y., et al. Improving the technology of processing sewing and knitwear production waste. Energy Procedia 2016:113:488-493. doi:10.1016/j.egypro.2017.04.047

[17] Kadnikova O. Y., Altynbayeva G. K., Aidarkhanov A. M., Shaldykova B. A. Sposob pererabotki sriva trikotazha. R.Kz. Patent 102864. July 15, 2016.

[18] Kadnikova O. Y., Altynbayeva G. K., Aidarkhanov A. M., Shaldykova B. A. Sposob obrabotki povtorno ispolzuemoj prjazhi. Positive decision to grant a patent for invention. Reg. No. 2017/0256.1.

[19] Kadnikova O. Y. Development of device for steaming and drying recycled yarn. Science and Peace 2015:8(24):37-39.

[20] Kadnikova O. Y. K voprosu o neobhodimosti razrabotok novyh tehnologij po pererabotke othodov legkoj promyshlennosti. Novoe Slovo v Nauke: Perspektivy Razvitija 2015:3:178-180. (in Russian)

[21] Khabdullin A., Khabdullina Z., Khabdullin A., Khabdullina G., Lauka D., Blumberga D. Analysis of Industrial Electricity Consumption Flexibility. Assessment of Saving Potential in Latvia and Kazakhstan. Energy Procedia 2016:113:450-453. doi:10.1016/j.egypro.2017.04.037

[22] Khabdullin A., Khabdullina Z., Khabdullina G., Lauka D., Blumberga D. Demand response analysis methodology in district heating system. Energy Procedia 2017:128:539-543. doi:10.1016/j.egypro.2017.09.004

[23] Francmanis E., Khabdullin A., Khabdullin A., et al. Comparative environmental analysis of microbial electrochemical systems. Energy Procedia 2015:95:564-568. doi:10.1016/j.egypro.2016.09.086

[24] Kadnikova O. Y., Altynbayeva G., Aidarkhanov A., et al. Potential analysis of implementation of developed technology for processing of sewing and knitting fabrics. Energy Procedia 2017:128:411-417. doi:10.1016/j.egypro.2017.09.047

[25] Kadnikova O. Y., Shaldykova B. A. Issledovanie vzaimosvjazej pokazatelej kachestva prjazhi. Nauka I mir 2016:1:7(35):46-49. (in Russian).

[26] Zhang L. Application of Probability and Mathematical Statistics in Enterprise Risk Analysis. Proceedings of 2015 International Conference on Education, Management and Computing Technology (ICEMCT). 2015:30:673-677. doi:10.2991/icemct-15.2015.141

[27] Khabdullin A., Khabdullin A., Khabdullina Z., Khabdullina G. Mathematical model of synchronous motors for static characteristics power loss. Energy Procedia 2015:95:487-490. doi:10.1016/j.egypro.2016.09.073 